\title{
Undergraduate radiology education in private and public teaching hospitals in Karachi, Pakistan: teaching duties, methodologies, and rewards
}

This article was published in the following Dove Press journal:

Advances in Medical Education and Practice

20 March 2013

Number of times this article has been viewed

\author{
Naila Nadeem ${ }^{1, *}$ \\ Ranish Deedar Ali \\ Khawaja ${ }^{2,3, *}$ \\ Madiha Beg' \\ Muhammad Naeem ${ }^{4}$ \\ Zain Majid ${ }^{4}$ \\ 'Department of Radiology, ${ }^{2}$ Aga Khan \\ University Hospital, Karachi, Pakistan; \\ ${ }^{3}$ Massachusetts General Hospital, \\ Harvard Medical School, Boston, \\ USA; ${ }^{4}$ Dow Medical College, Dow \\ University of Health Sciences, Karachi, \\ Pakistan \\ *These authors contributed equally \\ to this work
}

Correspondence: Ranish Deedar Ali Khawaja

I3 Holmes Street, Cambridge

MA 02138 , USA

Tel +I 8572047450

Fax + I 6177240046

Email ali.ranish@gmail.com
Background: In an integrated method of education, medical students are introduced to radiology in their preclinical years. However, no study has been conducted in Pakistan to demonstrate an academic framework of medical radiology education at an undergraduate level. Therefore, we aimed to document and compare the current level of teaching duties, teaching methodologies, and teaching rewards among radiologists and residents in private and public teaching hospitals in Karachi, Pakistan.

Methods: A survey was conducted among 121 radiologists and residents in two private and two public teaching hospitals in Karachi, Pakistan. Radiologists who were nationally registered with the Pakistan Medical and Dental Council either part-time or full-time were included. Radiology residents and fellows who were nationally registered with the Pakistan Medical and Dental Council were also included. Self-administered questionnaires addressing teaching duties, methods, and rewards were collected from 95 participants.

Results: The overall response rate was 78.51\% (95/121). All of the radiologists were involved in teaching residents and medical students, but only $36 \%$ reported formal training in teaching skills. Although most of the respondents (76\%) agreed that medical students appeared enthusiastic about learning radiology, the time spent on teaching medical students was less than five hours per week annually ( $82 \%$ ). Only $37 \%$ of the respondents preferred dedicated clerkships over distributed clerkships (41\%). The most common preferred teaching methodology overall was one-on-one interaction. Tutorials, teaching rounds, and problem-based learning sessions were less favored by radiologists than by residents. Teaching via radiology films (86\%) was the most frequent mode of instruction. Salary (59\%) was the most commonly cited teaching reward. The majority of respondents $(88 \%)$ were not satisfied with their current level of teaching rewards.

Conclusion: All radiologists and residents working in an academic radiology department are involved in teaching undergraduate students at multiple levels. The most valued teaching methodology involves use of images, with one-on-one interaction between the trainer and trainee. The monetary reward for teaching is inbuilt into the salary. The methodology adopted for teaching purposes was significantly different between respondents from private hospitals and those from public teaching hospitals. Because of low satisfaction among the respondents, efforts should be made to provide satisfying teaching rewards.

Keywords: radiology, hospital, department, medical faculty, teaching hospital

\section{Introduction}

In the integrated method of education, medical students are introduced to radiology in their preclinical years. ${ }^{1,2}$ This requires a task force of radiologists to monitor the radiology curriculum. Dedicated radiology teaching has been shown to improve medical 
students' performance in image interpretation in US and UK studies. ${ }^{1,3,4}$ There is a lack of evidence from South East Asia and the Subcontinent, especially Pakistan, focusing on the academic teaching perspective in the field of diagnostic radiology.

Undergraduate radiology education is not given a prime place in most medical school curricula, either nationally or globally. ${ }^{5,6}$ A Japanese study assessed student perceptions and evaluation of one of their radiology teaching methods, ie, lectures. They reported student curiosity and feedback from students to be highly correlated with their performance in examinations. ${ }^{7}$ In one institution in the United Arab Emirates, medical students perceived diagnostic radiology in an integrated curriculum as being both satisfactory and facilitative. ${ }^{8}$ In Pakistan, with its limited health care resources, understanding the indications and clinical effectiveness of imaging tests holds pivotal significance for our future practicing physicians. In such settings, effective evidence-based teaching methodologies are required for optimum patient care. ${ }^{9}$ The Pakistan Medical and Dental Council provides a fixed curriculum with a flexible framework aiming to train medical graduates with respect to requesting and interpretation of x-rays, ultrasound, computed tomography, and magnetic resonance imaging. Altogether, 40 hours over five years is regarded as mandatory teaching time for radiology. Because of a flexible framework, medical colleges have versatility in teaching methodologies for undergraduate students. ${ }^{5,10}$

Huda et al report both a scarcity of academic radiologists in the country, and relatively few medical students applying for postgraduate radiology training. ${ }^{11}$ Therefore, there is a fundamental need for evidence regarding the current level of teaching duties and commitment towards undergraduate radiology education on the part of radiologists and radiology residents in the developing world.

This study had the two-fold objectives of documenting and comparing the teaching profile, teaching duties, and commitment of radiologists and residents in public and private teaching hospitals, and comparing teaching methodologies and rewards between radiologists and residents in public and private teaching hospitals in Karachi, Pakistan.

\section{Materials and methods}

We conducted a cross-sectional study in four tertiary care teaching hospitals in Karachi, Pakistan. Data were collected from January to March 2011. We randomly enrolled two public (from a total of ten) and two private (from a total of five) teaching hospitals in Karachi registered with the Pakistan Medical and Dental Council. Using the departmental lists of the participating institutions, we enrolled a total of 121 subjects, which included all radiologists and residents at four selected teaching hospitals. ${ }^{12}$ These included 35 radiologists and 36 residents in private hospitals and 18 radiologists and 32 residents in public hospitals. The study was approved by the departmental research committee of the parent institution. Subjects were enrolled after informed consent was received from heads of department via mail. Confidentiality of both the participants and the teaching hospitals was strictly maintained throughout the study. A questionnaire was developed by the principal investigators and coinvestigators based on an extensive review of similar work done internationally. ${ }^{1-4,8,9}$ Demographic information about respondents, the academic profiles of the radiologists and residents, and their teaching commitments, duties, methods, and appraisal of rewards were elicited by questionnaire. This self-administered questionnaire was distributed to each respondent in person, and was collected personally by the investigators with the informed consent of the study participants. The questionnaire was pretested on $5 \%$ of the sample by the principal investigator, and a few changes were made and subsequently modified.

\section{Selection of participating institutions}

We obtained a list of teaching hospitals in Karachi, Pakistan, from the Higher Education Commission and randomly enrolled two public (from a total of ten) and two private (from a total of five) teaching hospitals registered with the Pakistan Medical and Dental Council.

\section{Selection of participants}

A list of radiologists and residents was obtained from the radiology department of each institution in order to define our sampling frame. The participants were then enrolled into the study.

\section{Sample size calculation}

In the absence of any robust data, assuming 50\% prevalence, a $95 \%$ confidence level, an error bound of $12 \%$, a study design effect of 1.5 , and a $10 \%$ refusal rate, the estimated sample size was calculated to be at least 111 individuals. The following formula was used to calculate the sample size:

$$
n=\left[\operatorname{DEFF}^{*} \mathrm{~Np}(1-\mathrm{p})\right] /\left[\mathrm{d}^{2} / \mathrm{Z}^{2}{ }_{1-\alpha / 2} *(\mathrm{~N}--1)+\mathrm{p} *(1-\mathrm{p})\right]
$$

See Appendix I for a better understanding of the study methods and interpretation of study results. It describes academic and clinical practice in the specialty of radiology 
in Pakistan, including the radiology postgraduate education system, medical undergraduate education system, and undergraduate radiology curriculum in Pakistan.

\section{Statistical analysis}

Data entry and analysis was done using the Statistical Program for Social Sciences (SPSS) version 19.0 (SPSS Inc, Chicago, IL, USA). Categorical variables are reported as the number (percentage). Analysis of categorical data was done using the Chi-square test and Fisher's Exact test. $P<0.05$ was considered to be statistically significant.

\section{Results}

\section{Study demographics}

Of 121 radiologists and residents in our participating institutions, 95 consented to participate in the study, giving an overall response rate of $78.51 \%$. The respondents included full-time radiologists (28.4\%), part-time radiologists (12.6\%), and residents $(58.9 \%)$, of mean age $33.64 \pm 6.97$ years, with females representing $56 \%$ of responders (53/95). Table 1 compares the study demographics between radiologists and residents in public and private teaching hospitals.

\section{Teaching profile}

Most of the radiologists (64\%) completed their residency training in public teaching hospitals. Radiologists in private teaching hospitals were more likely to have prior experience in teaching residents and fellows compared with their

Table I Demographics of radiologists and residents in private and public teaching hospitals $(n=95)$

\begin{tabular}{|c|c|c|}
\hline & $\begin{array}{l}\text { Radiologists } \\
n=39\end{array}$ & $\begin{array}{l}\text { Residents } \\
\mathrm{n}=56\end{array}$ \\
\hline Number of participants, n (\%) & $39(100)$ & $56(100)$ \\
\hline Full-time & $27(69)$ & - \\
\hline Part-time & $12(31)$ & - \\
\hline \multicolumn{3}{|l|}{ Setting of workplace, n (\%) } \\
\hline Private hospital & 31 (79) & $30(54)$ \\
\hline Public hospital & $8(2 I)$ & $26(46)$ \\
\hline \multicolumn{3}{|l|}{ Medical college training, n (\%) } \\
\hline Private hospital & $10(26)$ & $15(27)$ \\
\hline Public hospital & $29(74)$ & $4 \mid(73)$ \\
\hline \multicolumn{3}{|l|}{ Residency training, n (\%) } \\
\hline Private hospital & $17(44)$ & $30(54)$ \\
\hline Public hospital & $18(46)$ & $26(46)$ \\
\hline \multicolumn{3}{|l|}{ Total teaching experience } \\
\hline$<5$ years & $08(2 \mathrm{I})$ & $56(100)$ \\
\hline$\geq 5$ years & 31 (79) & $00(00)$ \\
\hline $\begin{array}{l}\text { Prior experience in medical } \\
\text { education, } n(\%)\end{array}$ & $39(100)$ & $34(61)$ \\
\hline $\begin{array}{l}\text { Previous training for teaching } \\
\text { skills, } n(\%)\end{array}$ & $14(36)$ & $27(48)$ \\
\hline
\end{tabular}

counterparts in public teaching hospitals (90\% versus $53 \%$; Chi-square value $37.424 ; \mathrm{df}=1 ; P \leq 0.001)$. The average teaching experience for most of the radiologists was more than five years $(79 \%$, Table 1$)$. The majority of the residents (61\%) undertook medical student teaching during their training. More residents from private teaching hospitals were trained in teaching skills compared with their colleagues trained in public teaching hospitals (Table 1).

\section{Teaching duties and commitment of radiologists}

Most of the radiologists (87\%) agreed that medical students appeared interested in learning radiology. Full-time academic radiologists preferred to train residents, followed by medical students and fellows. Part-time academic radiologists practicing in private teaching hospitals showed an equal preference for all three training groups. Those in private teaching hospitals were more likely to prefer medical students for radiology teaching than were their colleagues in public teaching hospitals (82\% versus 44\%, Chi-square value 14.475 ; $\mathrm{df}=1$; $P \leq 0.001$, Figure 1).

Overall, respondents in private teaching hospitals were more likely to spend less than 5 hours per week on teaching medical students, whereas respondents in public teaching hospitals were more likely to spend five or more than five hours per week (Chi-square value 30.653; $\mathrm{df}=1$; $P \leq 0.001)$. Overall, time spent by radiologists on teaching medical students was less than five hours per week annually, with only $10 \%$ spending more than ten hours per week annually.

Most of the radiologists (56\%) preferred teaching medical students only during regular clinical hours compared with $38 \%$ who were using designated academic hours for teaching purposes (Table 2).

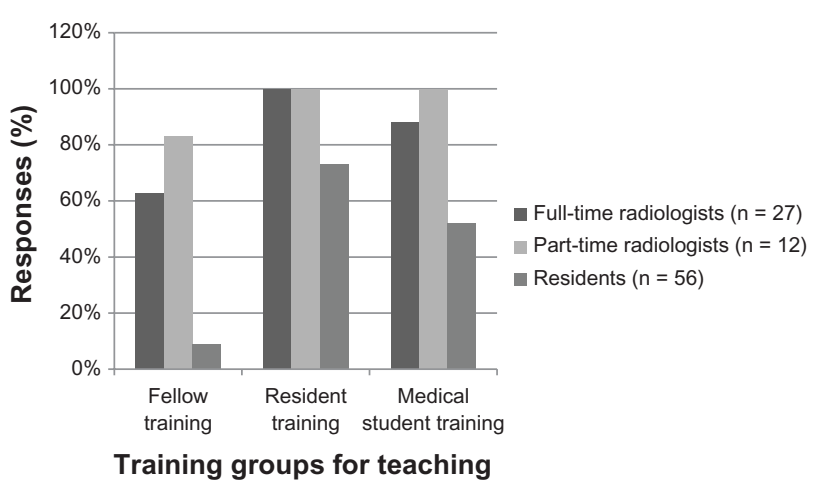

Figure I Teaching preferences among various training groups by radiologists and residents in teaching hospitals $(n=95)$. 
Table 2 Teaching duties by respondents (radiologists and residents) in private and public teaching hospitals $(n=95)$

\begin{tabular}{|c|c|c|c|c|c|}
\hline Teaching duties & $\begin{array}{l}\text { Respondents in } \\
\text { private hospitals } \\
n=6 I\end{array}$ & $\begin{array}{l}\text { Respondents in } \\
\text { public hospitals } \\
n=34\end{array}$ & $\begin{array}{l}\text { Chi-square } \\
\text { value }\end{array}$ & $\mathrm{dF}^{*}$ & $P$ value $\S$ \\
\hline \multicolumn{6}{|c|}{ Prior experience in medical } \\
\hline education, n (\%) & $55(90)$ & $18(53)$ & 37.424 & 1 & $<0.001$ \\
\hline \multirow{2}{*}{\multicolumn{6}{|c|}{$\begin{array}{l}\text { Time spent teaching medical } \\
\text { students per week, } n(\%)\end{array}$}} \\
\hline & & & & & \\
\hline$<5$ hours/week & $60(98)$ & $18(53)$ & 30.653 & 1 & $<0.001$ \\
\hline$\geq 5$ hours/week & $0 \mathrm{I}(\mathrm{I})$ & $16(47)$ & & & \\
\hline \multirow{2}{*}{\multicolumn{6}{|c|}{$\begin{array}{l}\text { Time spent in teaching material } \\
\text { preparation per week, } \mathrm{n}(\%)\end{array}$}} \\
\hline & & & & & \\
\hline$<5$ hours/week & $50(82)$ & $18(53)$ & 9.049 & 1 & 0.003 \\
\hline$\geq 5$ hours/week & II (I8) & $16(47)$ & & & \\
\hline
\end{tabular}

Notes: *Degrees of freedom; $\$ P$ value calculated via Pearson's Chi-square test.

Most of the residents (66\%) agreed that medical students appear interested in learning radiology, and preferred teaching junior residents (73\%) more than medical students (52\%). The time spent by residents on teaching medical students was less than five hours per week annually, with only $2 \%$ spending more than ten hours per week annually (Figure 1).

\section{Teaching methodology, curriculum, and evaluation}

The teaching methodology most preferred by radiologists and residents was one-on-one interaction $(P=0.029)$. The next most frequently preferred teaching methodologies were observation of clinical work at an individual level and problembased group sessions in public teaching hospitals. In both private and public teaching hospitals, the teaching methodologies preferred by significantly more radiologists than residents were multidisciplinary conferences and lectures $(P=0.001$ and $P=0.003$, respectively). Teaching via radiology films (86\%) was the most common mode of instruction in radiology, followed by use of computers and PowerPoint presentations (76\%). However, there was a significant difference in use of computers as a mode of instruction between private and public teaching hospitals ( $80 \%$ versus 59\%; Chi-square value 5.079; $\mathrm{df}=1 ; P=0.024)$. Picture archiving and communication systems were more likely to be used as a teaching method in private (74\%) than in public (59\%) teaching hospitals. Only $37 \%$ of respondents preferred dedicated clerkships over distributed clerkships (41\%). In all, $22 \%$ of respondents considered that both types of clerkship were equally effective.

\section{Teaching rewards for radiologists and residents}

Salary (59\%) followed by recognition in the department $(20 \%)$ and at the university level $(20 \%)$ were the major teaching rewards cited by faculty and residents. Most of the respondents (88\%) were not satisfied with their current level of teaching rewards.

\section{Discussion}

To the authors' knowledge, this survey is the first of its kind in Pakistan and encompasses several aspects of academic radiology, including teaching commitments and duties. Our study found an average teaching time of less than five hours per week annually. Radiologists spend considerable amounts of time preparing for lectures, tutorials, and facilitating multidisciplinary conferences in addition to one-on-one teaching. Residents teach during clinical work and on rounds. We have previously published data showing that students report insufficient time spent with radiologists, which may be attributed to interruptions from colleagues, residents, or technical staff. ${ }^{5}$ In a national survey of both academic and nonacademic radiologists in the US, Ding et al reported an average departmental teaching duration of 30 hours per week. ${ }^{13}$ In a survey of directors of medical school clerkships in the US, Samuel and Shaffer reported an average of nine hours per week for both teaching and administrative duties. ${ }^{14}$ Another study reported a total duration of radiology teaching time for medical students of 85 hours and 276 hours in Australia and New Zealand, respectively. ${ }^{15}$ The total duration was 170 hours for residents in radiology programs in Australia. ${ }^{15}$ The Pakistan Medical and Dental Council recommends 40 hours over the course of five years for teaching radiology exclusively to medical students. However, this is not practiced as a uniform norm. ${ }^{10}$

Baker et al surveyed radiology chairpersons in the US and reported that time spent on instruction of residents was longer than on educating students and fellows. ${ }^{16}$ However, another US study showed that the majority of teaching commitment 
was shown for medical students followed by residents and fellows. ${ }^{13}$ We found that plain films were the most common mode of technology used for teaching purposes, and that picture archiving and communication systems were being used as a teaching modality only in private teaching hospitals. In the US, the most commonly used teaching modality in radiology education was the integrated computer-based approach, followed by digital imaging and picture archiving and communication systems. ${ }^{17}$ When teaching via observation of radiology images, it should be ensured that the student-to-faculty ratio is kept very small, to enable dedicated teaching without hindering adequate view. ${ }^{5}$

The demands on today's radiologists have increased because of the pressure to earn money, and incentives are the only way to encourage people to work harder. This "carrot and stick" model of reward and punishment when used appropriately can result in better work productivity. ${ }^{18,19}$ One study emphasized that financial incentives greatly improve work production. ${ }^{20}$ Our survey reported salary as the most common teaching incentive for both radiologists and residents. Salary structure in the public sector is fixed according to number of years of service and position in the academic hierarchy. In the private sector, the salary structure was different in the two hospitals used in our study. In one hospital, salaries were fixed according to academic position. In the other one, salaries were partly fixed on the basis of academic position and partly on clinical workload. Most respondents were dissatisfied with their present level of teaching rewards. Another study showed that most of the institutions in the US provided no additional time off, with none to insignificant rewards for teaching. ${ }^{14}$ Ding et al reported that $45 \%$ of their respondents were not funded for their full time equivalents of teaching, with just over $7 \%$ of teaching being funded. In the same study, it was emphasized that compensated allotted academic time may help offset the lack of dedicated educational resources for teaching in radiology departments. ${ }^{13}$ Medical schools can retain their best faculty by defining pathways and criteria for rewarding their teaching efforts, ${ }^{21}$ with recognition of educational activity at the time of promotion.

Our study provides a snapshot of various aspects of academic radiology in Pakistan. However, we believe that a larger and more diverse sample of radiologists and residents from different regions of the country would have provided more generalizable results. The limitations of this study include its relatively small sample size and participants limited to teaching hospitals in only one region of Pakistan. It is not clear whether the results of this study reflect the opinion of the entire radiology community in Pakistan, so nationwide surveys are needed to explore this particular issue further.

\section{Conclusion}

Although most radiologists responsible for academic training in Pakistan do not have significant teaching experience, they have been the main radiology education providers in the country at both undergraduate and postgraduate levels. Multiple teaching approaches are currently in use, with advanced teaching methods existing in private teaching hospitals. Rewards in the form of monetary incentives for educational activity and academic recognition at the university and national levels would motivate present day radiologists. We recommend a dedicated curriculum for training radiology mentors to boost radiology education in Pakistan.

\section{Acknowledgments}

We thank the heads of department of radiology at the teaching hospitals for participating in this research. We also appreciate the efforts of the radiologists and residents who contribute to radiology teaching and training at the participating hospitals and who consented to participate in this study.

\section{Disclosure}

The authors report no conflicts of interest in this work.

\section{References}

1. Dawes TJ, Vowler SL, Allen CM, Dixon AK. Training improves medical student performance in image interpretation. $\mathrm{Br} J$ Radiol. 2004;77:775-776.

2. Gunderman RB, Alexander S, Jackson VP, Lane KA, Siddiqui AR, Tarver RD. The value of good medical student teaching: increasing the number of radiology residency applicants. Acad Radiol. 2000;7: 960-964.

3. Chew FS, Relyea-Chew A. Distributed Web-supported radiology clerkship for the required clinical clerkship year of medical school: development, implementation, and evaluation. Acad Radiol. 2002;9: 713-720.

4. Relyea-Chew A, Chew FS. Dedicated core clerkship in radiology for medical student's development, implementation, evaluation, and comparison with distributed clerkship. Acad Radiol. 2007;14:1127-1136.

5. Nadeem N, Zafar AM, Ahmed MN. Instituting an undergraduate core clerkship in radiology: initial experiences in Pakistan. J Pak Med Assoc. 2009:59:170-173.

6. Ianni MJD, Walker ML. Radiology in medical school: a missing piece of the puzzle? McMaster University Medical Journal. 2006;3:48-50.

7. Hama Y, Kusano S. Teaching radiology to military nursing students. Mil Med. 2005;170:713-714.

8. Ekelund L, Elzubeir M. Diagnostic radiology in an integrated curriculum: evaluation of student appraisal. Acad Radiol. 2000;7:965-970.

9. Dillon JE, Slanetz PJ. Teaching evidence-based imaging in the radiology clerkship using the ACR appropriateness criteria. Acad Radiol. 2010;17:912-916.

10. Pakistan Medical and Dental Council. Curriculum of MBBS. Available from: http://www.pmdc.org.pk/LinkClick. aspx?fileticket=EKfBIOSDTkE\%3D. Accessed January 19, 2013. 
11. Huda N, Yousuf S. Career preference of final year medical students of Ziauddin Medical University. Educ Health (Abingdon). 2006;19: 345-353.

12. Pakistan Medical and Dental Council. Recognized medical colleges in Pakistan. Available from: http://www.pmdc.org.pk/AboutUs/ RecognizedMedicalDentalColleges/tabid/109/Default.aspx. Accessed January 19, 2013.

13. Ding A, Mueller PR. The breadth of teaching commitment in radiology departments: a national survey. J Am Coll Radiol. 2010;7:290-293.

14. Samuel S, Shaffer K. Profile of medical student teaching in radiology: teaching methods, staff participation, and rewards. Acad Radiol. 2000;7: 868-874.

15. Subramaniam RM, Kim C, Scally P. Medical student radiology teaching in Australia and New Zealand. Australas Radiol. 2007;51:358-361.
16. Baker SR, Oif E, Roy R, Meehan TM. A survey of radiology chairpersons' perceptions of the relative importance of education of medical students, residents, and fellows. AJR Am J Roentgenol. 2010;195:974-978.

17. Chew FS. Distributed radiology clerkship for the core clinical year of medical school. Acad Med. 2002;77:1162-1163.

18. Smith JN, Gunderman RB. Should we inform patients of radiology results? Radiology. 2010;255:317-321.

19. Teutsch C. Patient-doctor communication. Med Clin North Am. 2003;87: 1115-1145.

20. McLoud TC. Education in radiology: challenges for new millennium. AJR Am J Roentgenol. 2000;174:3-8.

21. Lown BA, Sasson JP, Hinrichs P. Patients as partners in radiology education: an innovative approach to teaching and assessing patient-centred communication. Acad Radiol. 2008;15:425-432. 


\section{Appendix I:Academic and clinical practice in radiology in Pakistan}

In Pakistan, full-time radiologists practice only in a single medical college-affiliated teaching hospital, and hold a primary academic appointment at the same hospital. On the other hand, part-time radiologists practice in multiple medical college-affiliated teaching hospitals and/or within private practice. Hence they may hold multiple academic appointments. Radiologists train medical students, residents, fellows, and staff members in the radiology department. According to the College of Physicians and Surgeons in Pakistan, one supervisor can supervise a maximum of eight residents at one time. They do teaching during clinical hours, or during specified academic times, such as morning and afternoon conferences, teaching rounds, and tutorials. Radiology teaching may be done via a combination of methodologies, such as one-on-one interaction between a radiologist and student, lectures, interactive tutorials, problem-based learning sessions, or simple observation of radiology films. Common teaching techniques used include radiology films, PowerPoint, picture archiving and communication systems, and websites.

\section{Postgraduate radiology education system in Pakistan}

The radiology residency program in Pakistan is a four-year course structured to provide practical and academic training in diagnostic and interventional radiology. The Pakistan Medical and Dental Council encourages involvement of residents in teaching of medical students. Several workshops on communication and interpersonal skills are held to strengthen the teaching skills of residents.

\section{Medical undergraduate education system in Pakistan}

The undergraduate medical education is a five-year program in all medical colleges of Pakistan. The first two years are considered preclinical while the later three are considered clinical years. Each medical college is affiliated with a teaching hospital. The teaching curriculum at each medical college is approved by the Pakistan Medical and Dental Council. Most of the public medical colleges follow a traditional didactic medical curriculum, while the majority of private medical colleges follow an integrated, problem-based learning curriculum. The student population in each class of a public medical college (300 medical students on average) is three times that of the student population in each class of a private medical college (100 students on average).

\section{Undergraduate radiology curriculum in Pakistan}

The undergraduate radiology curriculum in public medical colleges is taught via a distributed clerkship, whereby radiology instruction is integrated into medicine and surgery clerkships throughout the clinical years of medical education. On the other hand, dedicated core radiology clerkships exist in private medical colleges. At any point in time, a small group of 5-6 medical students rotate through the clerkship for two weeks during their clinical years. The core clerkship has been designed to be integrated into the curriculum in a way that reflects the needs of patients, the local community, and medical students. Undifferentiated physicians are anticipated to recommend imaging modalities to their patients which are well thought out and cost-effective. Only one private teaching institution has a two-week dedicated clerkship in addition to a distributed curriculum over the course of five years. All other teaching institutions have a distributed curriculum spread over five years.
Advances in Medical Education and Practice

\section{Publish your work in this journal}

Advances in Medical Education and Practice is an international, peerreviewed, open access journal that aims to present and publish research on Medical Education covering medical, dental, nursing and allied healthcare professional education. The journal covers undergraduate education, postgraduate training and continuing medical education

\section{Dovepress}

including emerging trends and innovative models linking education, research, and healthcare services. The manuscript management system is completely online and includes a very quick and fair peer-review system. Visit http://www.dovepress.com/testimonials.php to read real quotes from published authors.

Submit your manuscript here: http://www.dovepress.com/advances-in-medical-education-and-practice-journal 